\title{
Sustained productivity in recombinant Chinese Hamster Ovary (CHO) cell lines: proteome analysis of the molecular basis for a process-related phenotype
}

Paula Meleady ${ }^{1 *}$, Padraig Doolan ${ }^{1}$, Michael Henry ${ }^{1}$, Niall Barron ${ }^{1}$, Joanne Keenan ${ }^{1}$, Finbar O'Sullivan ${ }^{1}$, Colin Clarke ${ }^{1}$, Patrick Gammell2, Mark W Melville ${ }^{3}$, Mark Leonard ${ }^{3}$ and Martin Clynes ${ }^{1}$

\begin{abstract}
Background: The ability of mammalian cell lines to sustain cell specific productivity (Qp) over the full duration of bioprocess culture is a highly desirable phenotype, but the molecular basis for sustainable productivity has not been previously investigated in detail. In order to identify proteins that may be associated with a sustained productivity phenotype, we have conducted a proteomic profiling analysis of two matched pairs of monoclonal antibody-producing Chinese hamster ovary $(\mathrm{CHO})$ cell lines that differ in their ability to sustain productivity over a 10 day fed-batch culture.

Results: Proteomic profiling of inherent differences between the two sets of comparators using 2D-DIGE (Difference Gel Electrophoresis) and LC-MS/MS resulted in the identification of 89 distinct differentially expressed proteins. Overlap comparisons between the two sets of cell line pairs identified 12 proteins (AKRIB8, ANXA1, ANXA4, EIF31, G6PD, HSPA8, HSP90B1, HSPD1, NUDC, PGAM1, RUVBL1 and CNN3) that were differentially expressed in the same direction.

Conclusion: These proteins may have an important role in sustaining high productivity of recombinant protein over the duration of a fed-batch bioprocess culture. It is possible that many of these proteins could be useful for future approaches to successfully manipulate or engineer $\mathrm{CHO}$ cells in order to sustain productivity of recombinant protein.
\end{abstract}

\section{Background}

Chinese hamster ovary $(\mathrm{CHO})$ cells are the most widely used vehicle for the production of biopharmaceuticals due to their high productivity, robust nature, track record in industry, and their safety record [1]. There has been considerable success in developing high-producing $\mathrm{CHO}$ cell culture processes using approaches such as optimisation of media formulation, improvements in expression vector design and also improvements in the design of bioreactors [2,3]. However, the bottlenecks in the cellular machinery for the efficient production of recombinant proteins are poorly understood. If there are

\footnotetext{
* Correspondence: paula.meleady@dcu.ie

${ }^{1}$ National Institute for Cellular Biotechnology, Dublin City University, Dublin 9, Ireland

Full list of author information is available at the end of the article
}

to be considerable improvements in increasing cellular productivity, a fundamental understanding of the biology underpinning productivity of these cells is required.

There have been a number of studies published using expression microarray and proteomic technologies to gain insights into the biology of mammalian cell lines used for biopharmaceutical production (reviewed $[4,5]$ ). Some studies have directly compared cell lines producing different levels of recombinant protein (from low to high producers) at one point in time, usually during the mid-exponential phase of growth [6-10]. Other studies have used profiling tools to deduce why media supplements such as butyrate [11-13] and DMSO [14], environmental conditions such as hyperosmotic pressure [15], or temperature shift [16], result in an increase in productivity. These studies have revealed many genes

\section{() Biomed Central}


and proteins that are altered under such conditions and are related to diverse biological functions such as protein folding and secretion, cell metabolism, cytoskeletal architecture, cell growth or apoptosis. However, very few of these studies have investigated the molecular mechanisms that enable a recombinant cell line to sustain high levels of cell specific productivity over the full duration of a culture period, although Stansfield et al. [17] found that while large changes in monoclonal antibody cell specific productivity (qMAB) occur during a fed-batch culture of GS-NS0 cells (up to 6-fold), the cellular proteome remained remarkably constant, varying primarily with cell growth rate.

In this study, we present a proteomic analysis focussing specifically on a sustained productivity phenotype over the entire production culture. Comparative analysis was carried out on two $\mathrm{CHO}$ production cell line pairs, with each pairing differing markedly in their ability to sustain high productivity of MAB over a ten day culture period. All four clonal cell lines used in the study initially demonstrated high cell specific productivities; however, two out of the four cell lines were unable to sustain Qp over the full 10 days of fed-batch culture, despite an optimised culture process being employed. The aim of this study was to identify key proteins that may be associated with the ability of $\mathrm{CHO}$ cells to sustain Qp in suspension culture over a 10 day fed-batch culture using 2D-DIGE (Difference Gel Electrophoresis) and LC-MS/MS.

\section{Methods}

\section{Cell culture and sample collection}

Four CHO MAB-secreting cell lines were used in the study; two cell lines which were able to sustain productivity (clone 3B12 and clone 2.8) and two cell lines which were unable to sustain productivity over 10 days in culture (clone 5B5 and clone 1.14). All four cell lines were derived from the same host lineage and bank (CHO K1). Clones 2.8 and 1.14 express the same monoclonal antibody and were derived from the same transfection event. Clones 3B12 and 5B5 each express different monoclonal antibodies. All four cell line samples were derived from $2 \mathrm{~L}$ bioreactor fed-batch cultures and were grown in identical proprietary serum-free media in suspension culture at $37^{\circ} \mathrm{C}$ followed by a temperature shift to $31^{\circ} \mathrm{C}$ after the initial exponential growth phase. All cell lines were seeded at a target seed density of $0.30 \times 10^{6}$ cells $/ \mathrm{mL}$ and cell counts from bioreactors were measured using a Cedex Automated Cell Culture Analyzer (Roche Innovatis). Samples for 2D-DIGE analysis were collected at Day 3 (pre-temperature shift) during the exponential growth phase, at Day 7 (stationary phase) and at Day 10 (late stationary/death phase). Three separate bioreactor runs were set up for each of the four cell lines. This allowed us to collect three biological replicate samples at each of the three time points for each of the four cell lines. The cell pellets containing $2 \times 10^{7}$ viable cells were washed twice with cold phosphate-buffered saline (PBS-A) solution and then stored at $-80^{\circ} \mathrm{C}$.

\section{Determination of cell-specific productivity ( $Q p)$}

The concentration of protein product in conditioned media samples (volumetric titre) was determined by Protein-A HPLC. Cell specific productivity (pg protein/ cell/day) (Qp) was determined by the following equation as recently published by our group [18].

$$
Q p(p g / \text { cell } / \text { day })=\left[\frac{\text { titre } 2-\text { titre } 1}{(\text { density } 2-\text { density } 1)}\right] \times \text { daily growth rate }
$$

where,

$$
\text { daily growth rate }=\left(\frac{\ln (\text { density } 2)-\ln (\text { density } 1)}{\text { time } 2-\text { time } 1}\right) / 24
$$

\section{D Difference Gel Electrophoresis (2D-DIGE)}

Frozen cell pellets containing $2 \times 10^{7}$ cells were thawed and resuspended in 500: $\mathrm{L}$ of lysis buffer (7 M urea, 2 $M$ thiourea, $30 \mathrm{mM}$ Tris, 4\% CHAPS, $5 \mathrm{mM}$ magnesium acetate, $\mathrm{pH}$ 8.5), and then homogenised by carefully passing the samples through a 20 gauge needle 5 times. Samples were left on a shaker for $1 \mathrm{hr}$ at room temp to allow extraction to take place, and then centrifuged at approximately 14,000 rpm (or equivalent g) for $15 \mathrm{~min}$ at $10^{\circ} \mathrm{C}$ to remove insoluble material. The supernatant was removed and stored at $-80^{\circ} \mathrm{C}$ until required for use. Protein concentrations were determined using the thiourea-compatible Bradford protein assay (Bio-Rad) and found to be similar among all samples. As a result, $50 \mu \mathrm{g}$ of protein was used per sample on each 2D-DIGE gel for comparative proteomic analysis experiments. Immobilized $18 \mathrm{~cm}$ linear $\mathrm{pH}$ gradient (IPG) strips (GE Healthcare), $\mathrm{pH}$ 4-7, were chosen for 2D-DIGE analysis as these gave good resolution of protein spots in a relatively broad pI range using the total cellular lysate protein extraction procedure described above. Previous optimisation experiments in our laboratory using 3-10 and $3-11$ NL IPG strips showed streaking in the basic pI range, hence the decision to use the pI 4-7 strips. However, it is recognised that any particular $\mathrm{pH}$ gradient and protein extraction procedure will resolve a limited number of proteins.

IPG strips were rehydrated in rehydration buffer (7 M urea, 2 M Thiourea, 4\% CHAPS, 0.5\% IPG Buffer, 50 mM DTT) overnight. Three biological replicate samples 
from each time point were labelled with either Cy3 (clones 1.14 and 5B5) or Cy5 (clones 3B12 and 2.8) dyes and a pooled internal standard was labelled with Cy2 dye to aid image matching and cross-gel statistical analysis [19]. Reverse labelling was also carried out on each sample to reduce dye bias. 2D-DIGE was then carried out according to manufacturer's instructions (GE Healthcare) and as previously described [7]. Gels were scanned with a Typhoon 9400 variable mode imager (GE Healthcare) and the subsequent Cy2, Cy3 and Cy5 gel images were analysed using the Differential In-gel Analysis (DIA) and Biological Variation Analysis (BVA) modules of DeCyder 6.5 software. Each experiment in the BVA module of Decyder 6.5 consisted of 36 gels including the Cy2-labelled images. Proteins were defined as differentially expressed if the observed average ratio was greater than $1.2, \mathrm{p}<0.01$. This relatively small fold change was chosen as previously it has been shown that small increases in the levels of ER luminal chaperone proteins can have a cumulative effect on the rate of protein folding and assembly, with an associated increase in productivity of MAB in GS-NSO cells [10].

\section{Protein identification by mass spectrometry}

LC-MS/MS was performed on an Ultimate 3000 nanoLC system (Dionex), interfaced to an LTQ Orbitrap XL (Thermo Fisher Scientific). 2D gel spots were excised from Coomassie-stained preparative gels containing $400 \mu \mathrm{g}$ of protein per gel, then destained with a solution containing $100 \mathrm{mM}$ ammonium bicarbonate/ acetonitrile $(\mathrm{ACN})(1: 1, \mathrm{vol} / \mathrm{vol})$ and incubated with occasional vortexing for $30 \mathrm{~min}$. Samples were then dehydrated by the addition of neat $\mathrm{ACN}$ and swelled by rehydration in a digestion buffer containing $12.5 \mathrm{ng} / \mu \mathrm{L}$ of trypsin (Promega, sequencing grade) in $10 \mathrm{mM}$ ammonium bicarbonate containing $10 \%$ (vol/vol) ACN at $37^{\circ} \mathrm{C}$ overnight. Peptides were extracted in extraction buffer (1:2 (vol/vol) $5 \%$ formic acid/ACN), incubated for $15 \mathrm{~min}$ at $37^{\circ} \mathrm{C}$ on a shaker and dried down in a vacuum centrifuge. Tryptic peptides were re-dissolved in $10 \mu \mathrm{L}$ of $0.1 \%$ formic acid containing $2 \% \mathrm{ACN} .5 \mu \mathrm{L}$ of sample was loaded onto a trapping column packed with C18, PepMAP100 (Dionex), at a flow rate of $20 \mu \mathrm{L} / \mathrm{min}$ in $0.1 \%$ formic acid. After 5 minutes of washing, peptides were eluted into a C18 PepMAP100 nanocolumn (15 $\mathrm{cm} \times 75 \mu \mathrm{m}$ ID, $3 \mu \mathrm{m}$ particles) (Dionex) at a flow rate of $350 \mathrm{~nL} / \mathrm{min}$. Peptides were separated using the mobile phase gradient: from 5 to $50 \%$ of solvent B in 30 min, and from 50 to $90 \%$ B in 5 min. Solvent A was 98:2 $\mathrm{H}_{2} \mathrm{O}: \mathrm{ACN}(\mathrm{v} / \mathrm{v})$ containing $0.1 \%$ formic acid; solvent $\mathrm{B}$ was $2: 98 \mathrm{H}_{2} \mathrm{O}: \mathrm{ACN}(\mathrm{v} / \mathrm{v})$ containing $0.1 \%$ formic acid. LC-MS/MS data was acquired in data-dependent acquisition (DDA) mode controlled by Xcalibur 2.0.7 software (Thermo Fisher Scientific). A typical DDA cycle consisted of an MS scan within $\mathrm{m} / \mathrm{z} 300-2000$ performed under the target mass resolution of 60,000 (full width at half maximum) followed by MS/MS fragmentation of the six most intense precursor ions under normalised collision energy of $35 \%$ in the linear trap. Database searches were performed using TurboSEQUEST software (Bioworks Browser v3.3.1) (Thermo Fisher Scientific) using the UniProtKB/SwissProt database (Swissprot fasta database was downloaded on 26/ 07/2010 at 21:41 from ftp://ftp.ncbi.nlm.nih.gov/blast/ $\mathrm{db} /$ FASTA). The following filters were applied: for charge state $1, \mathrm{X}_{\text {Corr }}>2.0$; for charge state $2, \mathrm{X}_{\text {Corr }}>$ 2.2 ; for charge state $3, \mathrm{X}_{\text {Corr }}>2.5$. Artificial modifications of peptides (carbamidomethylation of cysteines and partial oxidation of methionines) were considered. Searches were also carried out allowing for one missed cleavage. Protein identifications were accepted if they had at least 2 matched identified peptides and passed relevant statistical criteria.

\section{Western blotting}

$10 \mu \mathrm{g}$ of protein samples were prepared in SDS-PAGE sample buffer (Sigma), heated at $100^{\circ} \mathrm{C}$ for $5 \mathrm{~min}$ and cooled on ice prior to loading onto $12 \%$ NuPAGE BisTris gels (Invitrogen). Electrophoretic transfer, blocking and development of western blots were carried out as described previously [7]. Blots were probed with 1/5000 dilution of rabbit anti-human HSPD1 antibody (Abcam, ab46798) in Tris-buffered saline containing 0.1\% Tween 20 (TBST) and 1/5000 dilution in TBST of mouse antirabbit GAPDH monoclonal antibody (Abcam ab8245) (internal loading control).

\section{Results}

\section{Analysis of sustained MAB productivity over 10 days of} culture

Four CHO MAB-secreting cell lines were used in the study; two lines which were able to sustain productivity up to 10 days of culture were paired with two lines which were unable to sustain productivity over 10 days in culture. The cell lines which were able to sustain high productivity over 10 days in culture were labelled 'Sustained Qp (SQp)' and those that could not sustain high productivity were labelled 'Non-sustained Qp (NSQp)'. The paired comparisons were designated Cell Line Pair A (clones 3B12 (SQp) versus 5B5 (NSQp)) and Cell Line Pair B (clones 2.8 (SQp) versus 1.14 (NSQp)). The cell lines selected were paired as they were in an effort to minimize variables outside of the observed phenotype, as much as possible (see Materials and Methods above). Qp was measured for each cell line sample at Days 3, 7 and 10 (Figure 1A), and associated viable cell densities (VCDs) for each sample is shown in Figures $1 \mathrm{~B}$ and $1 \mathrm{C}$. In the two SQp cell lines, Qp remained high 
A

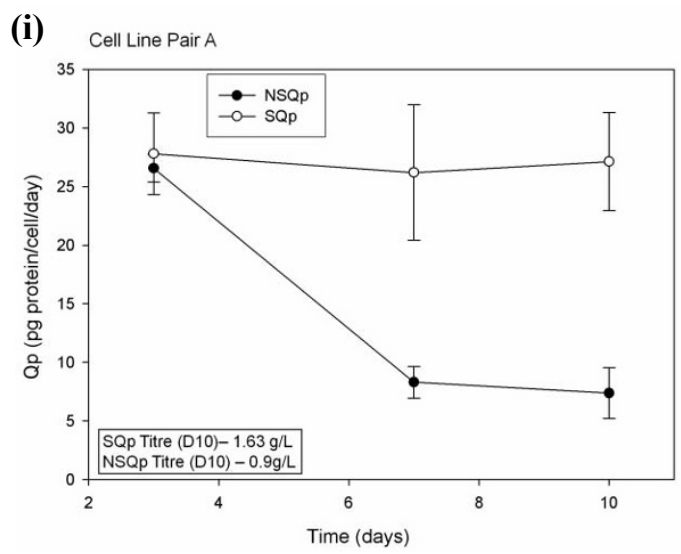

B

(i)

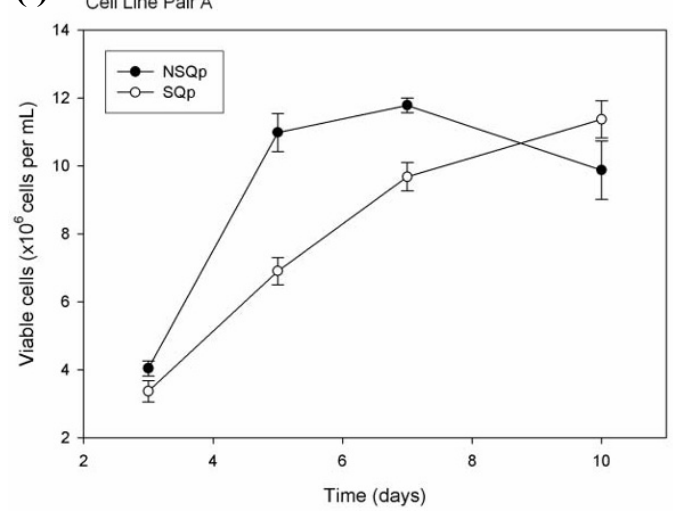

C

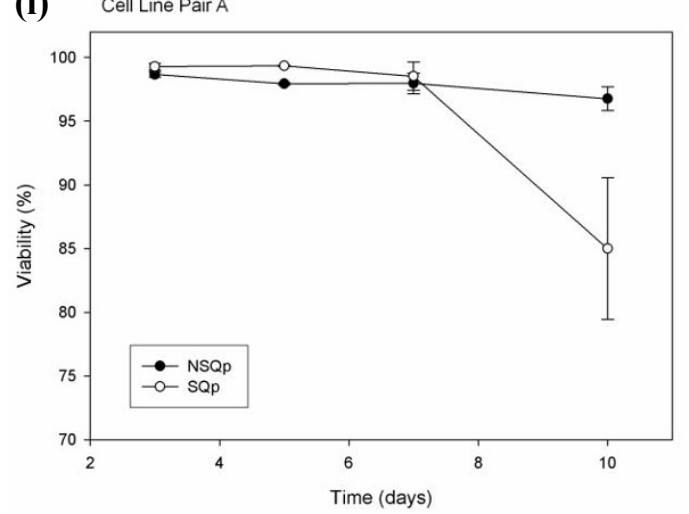

(ii) Cell Line Pair B

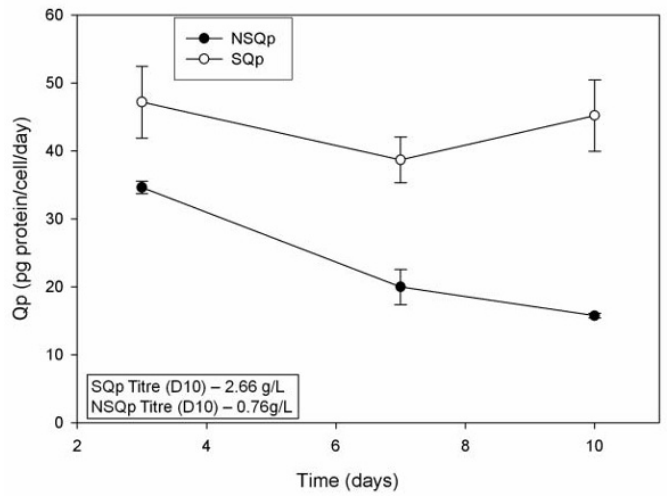

(ii) Cell Line Pair B

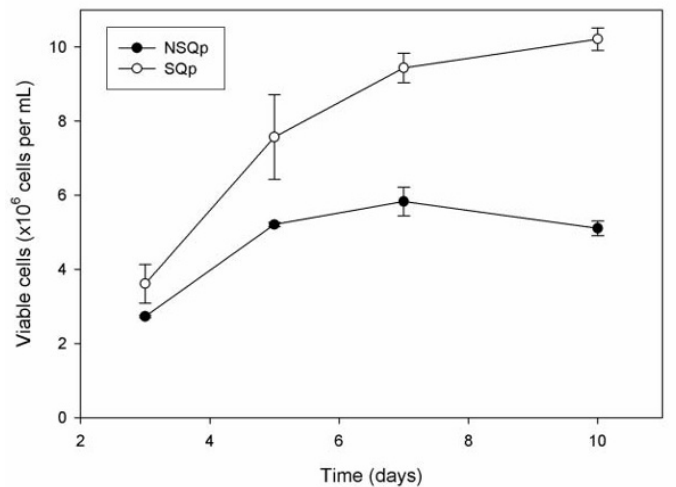

(ii)

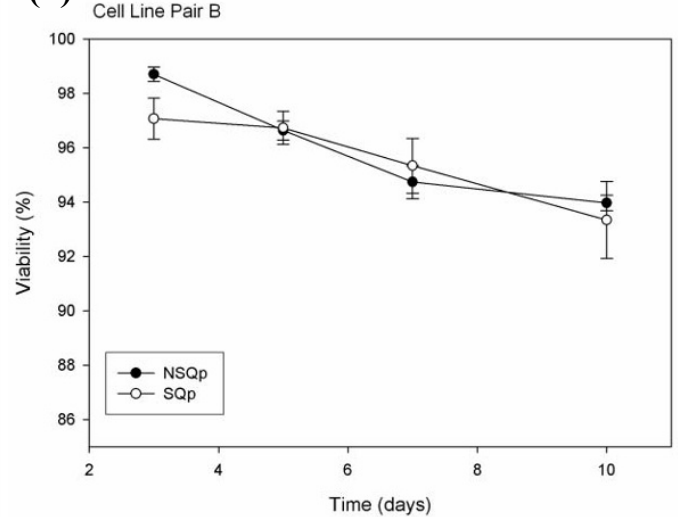

Figure 1 Qp measurements for each of cell line pairs A and B with associated viable cell densities. A. Qp measurements over time in culture for cell line pairs A and B. Qp measurements taken at days 3, 7 and 10. (i) Cell Line Pair A; (ii) - Cell Line Pair B. Final product titres measured at Day 10 (D10) are also included with the graphs. B. Growth and C. \% viability of each culture for cell line pairs A and B. Viable cell densities were taken at days 3, 5, 7 and 10; (i) - Cell Line Pair A; (ii) - Cell Line Pair B.

for the duration of the 10 day culture process. However in the case of the two NSQp cell lines, Qp fell dramatically by Day 7 and this decrease in Qp did not recover at Day 10. Therefore, these Qp measurements clearly show a difference between the cell line pairs A and B. The final product titres were also measured and calculated on Day 10 at the end of the process; for Cell Line Pair A these values averaged at $1.63 \mathrm{~g} / \mathrm{L}$ for the SQp 
and $0.9 \mathrm{~g} / \mathrm{L}$ for the NSQp cell lines; for Cell Line Pair B, product titres averaged at $2.66 \mathrm{~g} / \mathrm{L}$ for the SQp and 0.76 $\mathrm{g} / \mathrm{L}$ for the NSQp cell lines. From this data, the value of the sustained Qp phenotype is clear, i.e. in Cell Line Pair A where the initial Qp for both cell lines was similar and both cell lines grew to comparable VCDs, the SQp cell line generated 1.8-fold more protein over the duration of the culture through maintaining its Qp.

\section{Proteomic analysis of Cell Line Pairs A and B}

Two approaches were used to generate lists of differentially expressed proteins. In the first approach, as outlined in Figure 2A, individual time point samples were compared between the 'SQp' and 'NSQp' samples for each pair of cell lines (i.e. SQp Day 3 v NSQp Day 3, and similarly for Days 7 and 10). The second approach involved a time-course proteomic analysis, as outlined in Figure 2B, where 'SQp' or 'NSQp' samples from Day 7 and Day 10 were grouped together and compared with Day 3 samples for each pair of cell lines in order to look for protein expression changes that possibly tracked the SQp phenotype, i.e. showing altered expression at later stages of culture compared to Day 3. Both these approaches were used to gain an understanding of the inherent differences between the SQp and NSQp

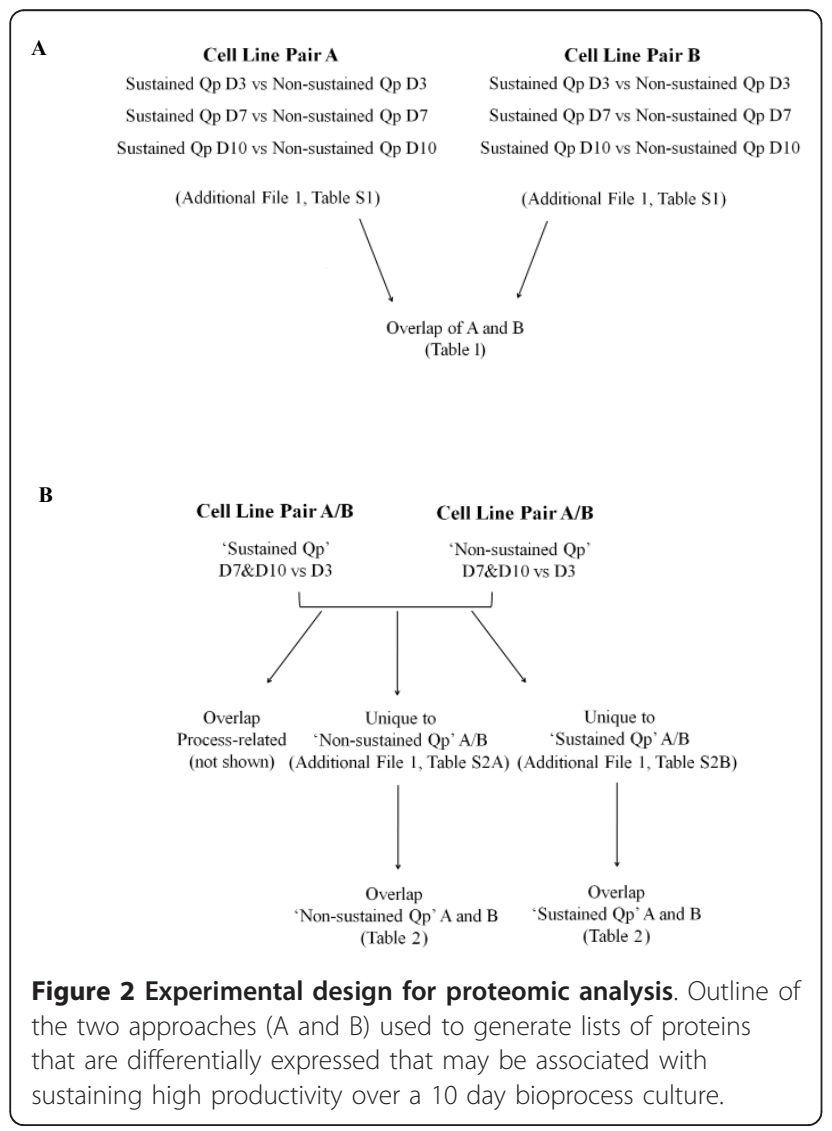

cell lines (Approach 1), and further see if there are protein changes in either the SQp or the NSQp cell lines that possibly 'track' the sustained productivity phenotype through a time course analysis of the samples (Approach 2).

For image analysis of the 2D-DIGE gels, the Differential In-gel Analysis (DIA) module of Decyder was first used to merge the Cy2, Cy3 and Cy5 images for each individual gel and to detect spot boundaries in order to calculate normalised spot volumes (protein abundance). The Biological Variation Analysis (BVA) module of Decyder was then used to match spot patterns across all gels for comparative cross-gel statistical analysis with protein abundance differences normalised against the $\mathrm{Cy} 2$ intensity for any given spot. Operator intervention was required at this stage for removal of spots arising from dust particles and other non-protein material. Landmarks were also manually defined in the gel to increase the accuracy of the spot matching algorithm. Comparison of normalised Cy3 and Cy5 spot volumes with the corresponding Cy2 standard spot volumes within each gel gave a standardised abundance. Each of the two experiments (i.e. Cell Line Pair A and Cell Line Pair B) in the BVA module of Decyder 6.5 consisted of 36 gels (18 for the NSQp cell line and 18 for the SQp cell line); this included three biological replicate gels plus a reverse labelled technical replicate gel for each cell line sample at the three time points. The number of detected spots on each gel averaged around 2000 per gel. After spot matching and filtering, 824 proteins were found to be present in all 36 gels for Cell Line Pair A and 1028 proteins present in all 36 gels for Cell Line Pair B. These protein spots were then used for subsequent comparative experiments within each cell line pair.

\section{Approach 1}

In the first approach, as outlined in Figure 2A, proteomic analyses of cell line pair A at each time point resulted in the identification of 58 differentially expressed proteins which are outlined in Additional File 1, Table S1. Similar analysis of cell line pair B resulted in the identification of 50 differentially expressed proteins and are also outlined in Additional File 1, Table S1. The proteins identified in these two lists from Cell Line Pairs A and B were overlapped to find common proteins differentially expressed between the paired comparisons, and these are outlined in Table 1 with the associated direction of expression (either increased or decreased). From Table 1, 16 proteins were found to be common between the two lists with 11 differentially expressed in the same direction, AKR1B8, ANXA1, ANXA4, EIF3I, G6PD, HSPD1, HSPA8, HSP90B1, NUDC, PGAM-1, and RUVBL1. Five proteins were differentially expressed in opposite directions, ALDH2, 
Table 1 List of differentially expressed proteins that are common between cell line pairs A and B by comparing all 'Non-sustained Qp (NSQp)' samples to 'Sustained Qp (SQp)' samples at days 3, 7 and 10.

\begin{tabular}{|c|c|c|c|c|}
\hline Accession no. & Gene Name & Protein Name & $\begin{array}{l}\text { Cell Line Pair A } \\
\text { Direction of expression (SQp v NQp) }\end{array}$ & $\begin{array}{l}\text { Cell Line Pair B } \\
\text { Direction of expression } \\
\text { (SQp v NQp) }\end{array}$ \\
\hline \multicolumn{5}{|c|}{ Proteins differentially regulated in the same direction } \\
\hline 008782 & AKR1B8 & Aldose reductase-related protein 2 & UP & UP \\
\hline P07150 & ANXA1 & Annexin A1 & DOWN & DOWN \\
\hline P97429 & ANXA4 & Annexin A4 & DOWN & DOWN \\
\hline Q13347 & ElF3| & Eukaryotic translation initiation factor 3 subunit 1 & UP & UP \\
\hline O55044 & G6PD & Glucose-6-phosphate 1-dehydrogenase & DOWN & DOWN \\
\hline P19378 & HSPA8 & Heat shock cognate $71 \mathrm{kDa}$ protein & UP & UP \\
\hline P14625 & HSP90B1 & Endoplasmin & UP, DOWN (2 spots on gel) & UP \\
\hline P18687 & HSPD1 & $60 \mathrm{kDa}$ heat shock protein, mitochondrial & UP & UP \\
\hline Q63525 & NUDC & Nuclear migration protein nudC & DOWN & DOWN (Day 7 only) \\
\hline Q9DBJ1 & PGAM1 & Phosphoglycerate mutase 1 & UP & UP \\
\hline Q9Y265 & RUVBL1 & RuvB-like 1 & UP & UP \\
\hline \multicolumn{5}{|c|}{ Proteins differentially regulated in the opposite direction } \\
\hline P47738 & $\mathrm{ALDH} 2$ & Aldehyde dehydrogenase, mitochondrial & UP & DOWN \\
\hline P29692 & EEF1D & Elongation factor 1-delta & UP & DOWN \\
\hline Q9Y230 & RUVBL2 & RuvB-like 2 & UP & DOWN \\
\hline Q64303 & PAK2 & Serine/threonine-protein kinase PAK 2 & DOWN & UP (Day 10 only) \\
\hline P48500 & TPI1 & Triosephosphate isomerase & DOWN & UP \\
\hline
\end{tabular}

Samples from all 3 time points were also combined into one analysis and compared. DOWN - decreased in the SQp cells compared to NSQp cells; UP - increased in SQp cells compared to NSQp cells. Accession number is from UniProtKB/Swiss-Prot protein database. The full protein lists from each cell line pair are in Additional File 1, Table S1.

EEF1D, RUVBL2, PAK2 and TPI. An example of the 2D-DIGE images from one of these proteins found to be differentially expressed in both comparators, Glucose 6 phosphate-1 dehydrogenase, (i.e. decreased at all time points in the SQp cell lines compared to the NSQp cell lines) is shown in Figure 3.

\section{Approach 2}

A time-course proteomic analysis was also carried out, as outlined in Figure 2B, where 'SQp' or 'NQp' samples from Day 7 and Day 10 were grouped together and compared with Day 3 samples for each pair of cell lines. The purpose of this analysis was to identify those proteins whose expression changes over the course of the production fed batch for each of the cell lines, and then separate those that are unique to the 'SQp' or 'NSQp' lines from those that are common to all cell lines and therefore are what we are calling 'process-related'. The 'SQp' and 'NSQp' lists from cell line pair A were overlapped to look for uniquely differentially expressed proteins. Proteins showing 'process-related' changes (i.e. proteins whose expression levels change as a result of culture conditions over time) in both 'SQp' and 'NSQp' cell lines were removed from the analysis. 14 proteins were identified as changed only in the 'NSQp' cell line, and 14 proteins identified as changed only in the 'SQp' cell line (see Additional File 1, Tables 2A and 2B) for cell line pair $\mathrm{A}$. The same approach was used for cell line pair B, with 10 proteins identified as changed only in the 'NSQp' cell line and 8 identified as changed only in the 'SQp' cell line (Additional File 1, Tables 2A and 2B). These two 'unique' lists from both cell line pairs were subsequently overlapped to identify a second list of proteins that may be linked with the ability of a cell line to sustain productivity over a 10 day bioprocess culture, and are outlined in Table 2. Overlapping the 'NSQp' lists between the two cell line pairs A and B revealed that two proteins, HSPD1 and EIF3I, were common to both comparators and were differentially expressed in the same direction in both cases (i.e. both decreased at days 7 and 10 compared to day 3). Similarly, the 'SQp' lists from both comparators were overlapped and two proteins, CNN3 and AKRIB8, were common to both lists and were both decreased at day 7 and 10 compared to day 3. Three of these proteins (HSPD1, EIF3I and AKRIB8) were also found to overlap with Table 1, reconfirming these proteins as potentially playing a role in sustaining recombinant protein production in $\mathrm{CHO}$ cell lines.

Figure 4 shows an example of one of these proteins, HSPD1, whose expression levels appear to follow a pattern of protein expression that mirrors the altered Qp of the cell line pairs over the 10 day culture process. In the case of the 'SQp' cell lines, HSPD1 protein expression remains constant over the three time 


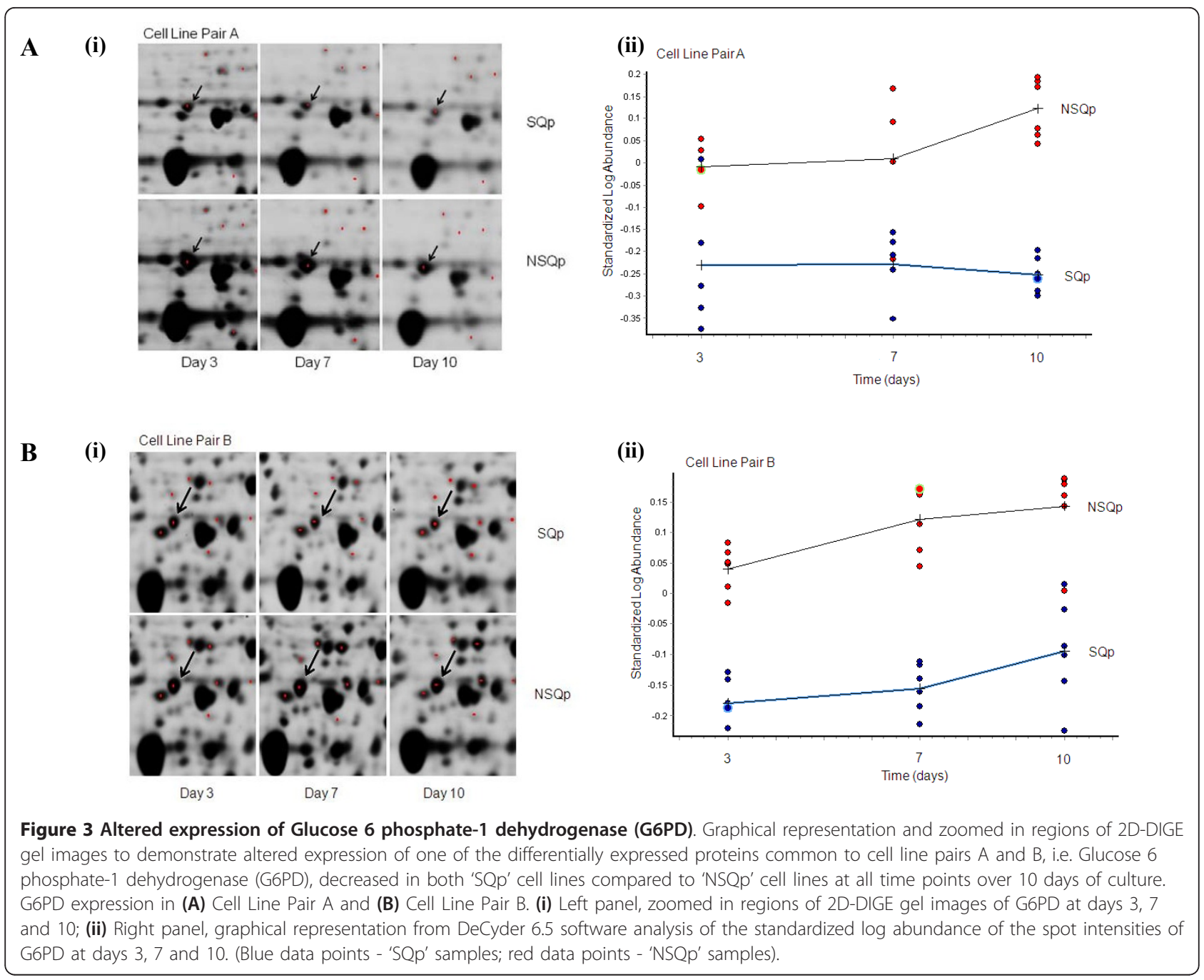

points while the levels appear to decrease at days 7 and 10 for the 'NSQp' cell lines (Figure 4A) similar to the fall off in Qp at days 7 and 10 for these cell line samples (Figure 1A). This was reconfirmed through western blot validation using an antibody against HSPD1 (Figure 4B).

\section{Overall summary of proteomic datasets}

Overall, proteomic analysis of the two cell line pairs has identified 154 proteins that are possibly related to a sustained productivity phenotype; (i.e. 58 for Cell Line Pair A and 50 for Cell Line Pair B in Additional File 1, Table S1, 24 proteins from Cell Line Pairs $A$ and $B$ in

Table 2 List of unique differentially expressed proteins that are common between cell line pairs A and B by comparing ‘Non-sustained Qp' or 'Sustained Qp' samples at Days $7 \& 10$ with Day 3 samples.

\begin{tabular}{|c|c|c|c|c|}
\hline Accession no. & Gene Name & Protein name & $\begin{array}{l}\text { Cell Line Pair A } \\
\text { (Direction of expression, } \\
\text { D7\&10 v D3) }\end{array}$ & $\begin{array}{l}\text { Cell Line Pair B } \\
\text { (Direction of expression, } \\
\text { D7\&10 v D3) }\end{array}$ \\
\hline \multicolumn{5}{|l|}{ Unique to NSQp } \\
\hline P18687 & HSPD1 & $60 \mathrm{kDa}$ heat shock protein, mitochondrial & Down & Down \\
\hline Q13347 & EIF3| & Eukaryotic translation initiation factor 3 subunit 1 & Down & Down \\
\hline \multicolumn{5}{|l|}{ Unique to SQp } \\
\hline P37397 & CNN3 & Calponin-3 & Down & Down \\
\hline 008782 & AKR1B8 & Aldose reductase-related protein 2 & Down & Down \\
\hline
\end{tabular}

DOWN - decreased in Day 7\&10 samples compared to Day 3 samples; UP - increased in Day $7 \& 10$ samples compared to Day 3 samples. Accession number is from UniProtKB/Swiss-Prot protein database. The full protein lists from each cell line pair are in Additional File 1, Table S2 (A and B). 


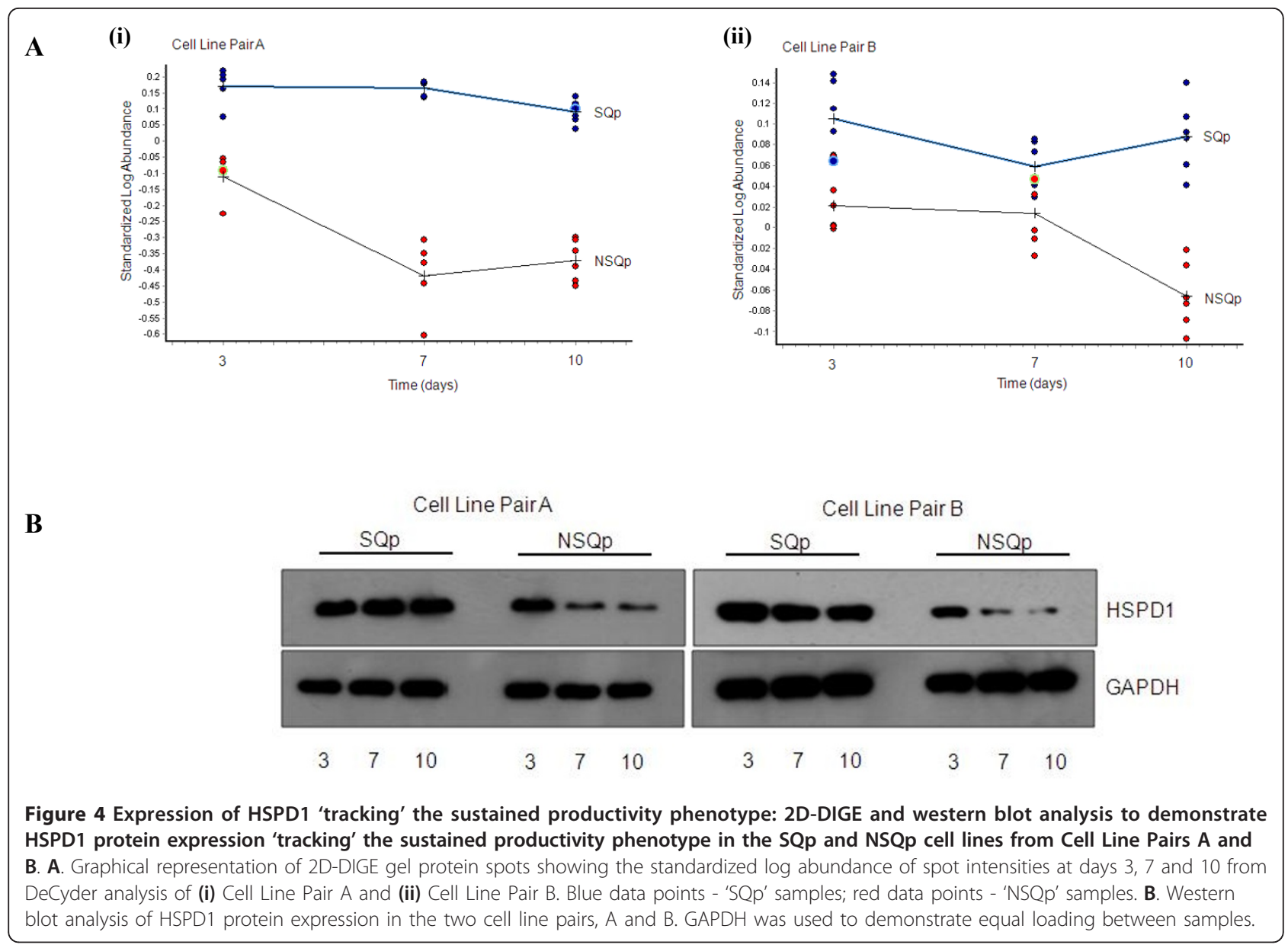

Additional File 1, Table S2A, and 22 proteins from Cell Line Pairs A and B in Additional File 1, Table S2B). These 154 proteins represent 89 distinct proteins due to overlap between the different lists and also due to the fact that a number of proteins, such as ALDH2, ANXA1, HSPA8, HSP90B, TCP1, VCP, RPSA, SERPINB1A, UBEK2, were identified more than once on the 2D gels which could be indicative of posttranslational modifications. For example, HSPA8 and VCP are both known to be potentially phosphorylated $[20,21]$. A number of the proteins from this list of 89 proteins (i.e. RPLP0, ENO1, CNN3, ANXA5, EEF1D, LGALS1, HSPA8, HSPB1, HMGCS1, NSFL1C, RPIA and TPT1) were found to overlap with a previous study from our laboratory related to proteomic profiling of low and high productivity phenotypes from recombinant $\mathrm{CHO}$ cells [7].

When combining the overlap lists (Tables 1 and 2) from the two proteomic analysis approaches used to yield a list of proteins potentially related to a sustained productivity phenotype, twelve of these 89 proteins were found to be differentially expressed in the same direction, i.e. AKRIB8, ANXA1, ANXA4, EIF3I, G6PD, HSPA8, HSP90B1, HSPD1, NUDC, PGAM1, RUVBL1 and $\mathrm{CNN} 3$.

\section{Discussion}

Cell specific productivity is a function of a multitude of cellular processes including gene transcription, mRNA stability, translation, glycosylation, polypeptide folding, ER-associated degradation and inter-vesicular transport of fully assembled proteins [5]. Few studies have investigated the molecular basis of how recombinant cell lines are capable of sustaining productivity of a product of interest over the duration of a culture process. From this study, we have identified 89 distinct proteins that are differentially expressed in two pairs of cell lines that substantially differ in their ability to sustain Qp over the full duration of an optimized, 10-day fed-batch culture. Overlapping the proteomic lists generated from analysis of the two cell line pairs revealed a list of 12 proteins, common between the two sets of analyses that were differentially regulated in the same direction (Tables 1 and 2). Some of these 12 proteins, particularly HSPD1 and 
EIF3I, were found to 'track' the sustained Qp phenotype, i.e. HSPD1 and EIF3I protein expression remained constant in the SQp cell lines, in contrast to the NSQp cell lines

From the 12 differentially expressed proteins, four of the proteins that show increased expression in the SQp cell lines are known to be involved in protein translation (EIF3I) [22] and protein folding (HSPD1, HSPA8 and HSP90) [23-25], suggesting that the SQp cell lines have possibly a greater efficiency in sustaining protein synthesis and folding of polypeptides over the duration of the 10 day bioprocess culture. HSPD1, HSPA 8 and HSP90 have all been previously been shown in other studies to have increased expression in higher producing cell lines $[9,10]$. HSPD1 (HSP60) is a member of the chaperonin family and is essential for the folding and assembly of newly imported proteins in the mitochondria [24]. Increased expression of HSPD1 has been found to be associated with increased MAB production in GS-NS0 cells [10]. HSPA8 is a member of the HSP70 protein family which is known to have anti-apoptotic properties [26]. As a result, HSPA8 has also been used as an engineering target to prolong culture viability resulting in increased product titre in a number of cell lines including $\mathrm{CHO}$, NS0 and BHK-21 [27-29]. HSP90B1 (also known as GRP94 or endoplasmin) is a highly conserved ER luminal molecular chaperone that has key roles in folding newly synthesized proteins or stabilizing and refolding denatured proteins after stress. HSP90 proteins normally interact with other co-chaperones as part of a multi-protein complex (with $\mathrm{BiP}$ ) associated with nascent Ig heavy chain synthesis in the ER [23,30]. Previous proteomic studies have shown that HSP90 exhibits an increase in abundance that correlates with increased qMAB in NS0 cells $[9,10]$.

The list of 12 overlapping proteins also included three proteins involved in glucose metabolism, with PGAM1 and AKRIB8 showing increased expression while G6PD showed decreased expression in both cell line pairs. G6PD (glucose 6 phosphate dehydrogenase) is involved in the production of NADPH, a key electron donor in the defense against oxidizing agents and in reductive biosynthetic reactions. PGAM1 is a glycolytic enzyme that catalyses the interconversion of 3-phosphoglycerate and 2-phosphoglycerate. AKRIB8 (aldo-keto reductase) is a phase I metabolising enzyme that catalyses the reduced nicotinamide adenine dinucleotide (phosphate) $(\mathrm{NAD}(\mathrm{P}) \mathrm{H})$-dependent reduction of carbonyl groups to yield primary and secondary alcohols on a wide range of substrates. It has been previously suggested based on proteomic analysis of high MAB productivity in NS0 cells, that up-regulation of processes such as energy metabolism may be involved in the improved production of MAB [31]. During B cell differentiation, B cells may anticipate their secretory role in a multistep process; firstly by up-regulating the expression of proteins involved in metabolism followed by an expansion of the secretory machinery to accommodate the mass production of antibodies [32]. It has also been previously suggested that the complex trait of hyperproductivity in recombinant mammalian cell lines could have some similarities to the differentiation of non-secretory $B$ cells to plasma cells [33] with higher producing cells requiring higher energy levels. Perhaps some parallels could be drawn to our study in that the cells that are able to sustain productivity have an increased metabolic capacity which enables them to sustain productivity of $\mathrm{MAB}$ over the duration of the 10 day bioprocess culture.

Other proteins with a variety of cellular functions present on the overlap list include RUVBL1, ANXA1, ANXA4, NUDC and CNN3. RUVBL1 is an ATP-binding protein that belongs to the $\mathrm{AAA}+$ family of ATPases, which have been implicated in a variety of cellular processes such as transcription, small ribonucleolar protein (snoRNPs) complex assembly, cellular transformation, metastasis and apoptosis [34]. ANXA1 and ANXA4 are both members of the annexin family of $\mathrm{Ca}$ (2+)-dependent phospholipid binding proteins. ANXA1 is involved in the regulation of cell proliferation and apoptosis $[35,36]$ while ANXA4 can promote membrane fusion and is involved in exocytosis [37]. NUDC (nuclear distribution gene homologue) plays a role in cell division through the regulation of cytoplasmic dynein [38]. Through its interaction with dynein NUDC is also involved in the perinuclear localization of the Golgi apparatus and lysosomes and endocytic vesicles transport [39]. CNN3 (calponin-3) is an actin-associated protein and is involved in cellular architecture and cell motility [40]. Further work on these proteins is required to understand the role they play in the sustained Qp phenotype.

\section{Conclusions}

We have described here the first attempt to unravel some of the molecular basis for a sustained high Qp phenotype in $\mathrm{CHO}$ cells. These proteins may be useful as biomarkers to pre-select cell line clones at an earlier stage of cell line development to enrich for clones with a stable Qp phenotype. Moreover, it is possible that many of these proteins could be successfully manipulated or engineered so as to elicit the very phenotype we have characterized. Indeed, individual target engineering may only be the first step into pathway engineering, as this phenotype is likely to represent a complex interplay between metabolic and signalling pathways. Nevertheless, the utility of biomarkers is that they provide a powerful tool for screening a diverse population of 
clones in order to identify those with predictably preferred characteristics. Future research into both of these investigational lines will be of great value to bioprocess science.

\section{Additional material}

\begin{abstract}
Additional File 1: Table S1: List of differentially expressed proteins identified by 2D-DIGE and LC-MS/MS from cell line pairs A and B by comparing 'Non-sustained $\mathbf{Q} p$ ' samples to 'Sustained $\mathbf{Q} \mathbf{p}^{\prime}$ samples at each time point. Ratios outlined in italics are for information only to show the general trend of protein expression, as they have not passed the statistical criteria outlined for DeCyder analysis of the 2D-DIGE images, i.e. average ratio greater than 1.2, $p<0.01$. Mass Spectrometry protein identifications were accepted if they had at least 2 matched identified peptides and passed relevant statistical criteria including $X$ Corr Scores (i.e. for charge state 1, $X_{\text {corr }}>2.0$; for charge state $2, X_{\text {Corr }}>2.2$; for charge state $3, X_{\text {corr }}>2.5$ ). Table S2: A. List of unique differentially expressed proteins identified by 2D-DIGE and LC-MS/MS from cell line pairs A and B by comparing 'Non-sustained $Q p^{\prime}$ cell lines at Days $7 \& 10$ with Day 3 samples. B. List of unique differentially expressed proteins identified from cell line pairs A and B by comparing 'Sustained Qp' cell lines at Days 7\&10 with Day 3 samples. Mass Spectrometry protein identifications were accepted if they had at least 2 matched identified peptides and passed relevant statistical criteria including XCorr Scores (i.e. for charge state $1, X_{\text {Corr }}>2.0$; for charge state $2, X_{\text {corr }}>2.2$; for charge state $3, X_{\text {Corr }}>2.5$ )
\end{abstract}

\section{List of Abbreviations}

CHO: Chinese Hamster ovary; MAB: Monoclonal antibody; VCD: viable cell density; SQp: sustained productivity; NSQp: non-sustained productivity; 2DDIGE: 2D differential gel electrophoresis; LC-MS: Liquid chromatography-mass spectrometry.

\section{Acknowledgements}

This work was supported by funding from Science Foundation Ireland (SFI) grant number 07/IN.1/B1323.

\section{Author details}

'National Institute for Cellular Biotechnology, Dublin City University, Dublin 9, Ireland. ${ }^{2}$ Bio-Manufacturing Sciences group, Pfizer, Inc., Grange Castle International Business Park, Clondalkin, Dublin 22, Ireland. ${ }^{3}$ Bioprocess R\&D, Pfizer Inc., 1 Burtt Rd, Andover, MA 01810, USA.

\section{Authors' contributions}

PM and MM designed the experimental approach. PM and JK carried out the 2D DIGE analysis. PM and $\mathrm{MH}$ did the mass spectrometry identification $P M, P D, N B, F O S, P G, C C, M M$ were involved with result interpretation and manuscript preparation. ML and $M C$ conceived the study and participated in the study design and coordination. All authors read and approved the final manuscript.

\section{Competing interests}

The authors declare that they have no competing interests. MM, PG and ML are employees of Pfizer.

Received: 30 March 2011 Accepted: 24 July 2011

Published: 24 July 2011

\section{References}

1. Chu L, Robinson DK: Industrial choices for protein production by largescale cell culture. Curr Opin Biotechnol 2001, 12:180-187.

2. Altamirano C, Paredes C, Cairó JJ, Gòdia F: Improvement of CHO cell culture medium formulation: simultaneous substitution of glucose and glutamine. Biotechnol Prog 2000, 16:69-75.
3. Prentice HL, Ehrenfels BN, Sisk WP: Improving performance of mammalian cells in fed-batch processes through "bioreactor evolution". Biotechnol Prog 2007, 23:458-464.

4. Meleady P: Proteomic profiling of recombinant cells from large-scale mammalian cell culture processes. Cytotechnology 2007, 53:23-31.

5. O'Callaghan PM, James DC: Systems biotechnology of mammalian cell factories. Brief Funct Genomic Proteomic 2008, 7:95-110.

6. Doolan P, Melville M, Gammell P, Sinacore M, Meleady P, McCarthy K, Francullo L, Leonard M, Charlebois T, Clynes M: Transcriptional profiling of gene expression changes in a PACE-transfected CHO DUKX cell line secreting high levels of rhBMP-2. Mol Biotechnol 2008, 39:187-199.

7. Meleady P, Henry M, Gammell P, Doolan P, Sinacore M, Melville M, Francullo L, Leonard M, Charlebois T, Clynes M: Proteomic profiling of CHO cells with enhanced rhBMP-2 productivity following co-expression of PACEsol. Proteomics 2008, 8:2611-2624.

8. Nissom PM, Sanny A, Kok YJ, Hiang YT, Chuah SH, Shing TK, Lee YY, Wong KT, Hu WS, Sim MY, Philp R: Transcriptome and proteome profiling to understanding the biology of high productivity $\mathrm{CHO}$ cells. $\mathrm{Mol}$ Biotechnol 2006, 34:125-140.

9. Seth G, Philp RJ, Lau A, Jiun KY, Yap M, Hu WS: Molecular portrait of high productivity in recombinant NSO cells. Biotechnol Bioeng 2007, 97:933-951.

10. Smales CM, Dinnis DM, Stansfield SH, Alete D, Sage EA, Birch JR, Racher AJ, Marshall CT, James DC: Comparative proteomic analysis of GS-NSO murine myeloma cells lines with varying recombinant monoclonal antibody production rate. Biotechnol Bioeng 2004, 88:474-488.

11. Baik JY, Lee GM: A DIGE approach for the assessment of differential expression of the $\mathrm{CHO}$ proteome under sodium butyrate addition: Effect of BCl-x(L) overexpression. Biotechnol Bioeng 2010, 105:358-367.

12. Kantardjieff A, Jacob NM, Yee JC, Epstein E, Kok YJ, Philp R, Betenbaugh M, Hu WS: Transcriptome and proteome analysis of Chinese hamster ovary cells under low temperature and butyrate treatment. J Biotechnol 2010, 145:143-159.

13. Yee JC, de Leon Gatti M, Philp RJ, Yap M, Hu WS: Genomic and proteomic exploration of $\mathrm{CHO}$ cells under sodium butyrate treatment. Biotechnol Bioeng 2008, 99:1186-1204.

14. Li J, Huang Z, Sun $X$, Yang $P$, Zhang Y: Understanding the enhanced effect of dimethyl sulfoxide on hepatitis B surface antigen expression in the culture of Chinese hamster ovary cells on the basis of proteome analysis. Enzyme Microb Technol 2006, 38:372-380.

15. Lee MS, Kim KW, Kim YH, Lee GM: Proteome analysis of antibodyexpressing $\mathrm{CHO}$ cells in response to hyperosmotic pressure. Biotechnol Prog 2003, 19:1734-1741.

16. Baik JY, Lee MS, An SR, Yoon SK, Joo EJ, Kim YH, Park HW, Lee GM: Initial transcriptome and proteome analyses of low culture temperatureinduced expression in $\mathrm{CHO}$ cells producing erythropoietin. Biotechnol Bioeng 2006, 93:361-371.

17. Stansfield SH, Allen EE, Dinnis DM, Racher AJ, Birch JR, James DC: Dynamic analysis of GS-NSO cells producing a recombinant monoclonal antibody during fed-batch culture. Biotechnol Bioeng 2007, 97:410-24.

18. Clarke C, Doolan P, Barron N, Meleady P, O'Sullivan F, Gammell P, Melville M, Leonard M, Clynes M: Predicting cell-specific productivity from CHO gene expression. J Biotechnol 2011, 151:159-65.

19. Alban A, David SO, Bjorkesten L, Andersson C, Sloge E, Lewis S, Currie I: A novel experimental design for comparative two-dimensional analysis: two-dimensional difference gel electrophoresis incorporating a pooled internal standard. Proteomics 2003, 3:36-44.

20. Ewens CA, Kloppsteck P, Förster A, Zhang X, Freemont PS: Structural and functional implications of phosphorylation and acetylation in the regulation of the AAA+ protein p97. Biochem Cell Biol 2010, 88:41-48

21. Lu Y, Hu Q, Yang C, Gao F: Histidine 89 is an essential residue for Hsp70 in the phosphate transfer reaction. Cell Stress Chaperones 2006. 11:148-153.

22. Hinnebusch AG: elF3: a versatile scaffold for translation initiation complexes. Trends Biochem Sci 2006, 31:553-562.

23. Melnick JH, Dul JL, Argon Y: Sequential interaction of the chaperones BiP and GRP94 with immunoglobulin chains in the endoplasmic reticulum. Nature 1994, 370:373-375.

24. Itoh H, Komatsuda A, Ohtani H, Wakui H, Imai H, Sawada K, Otaka M, Ogura M, Suzuki A, Hamada F: Mammalian HSP60 is quickly sorted into the mitochondria under conditions of dehydration. Eur J Biochem 2002, 269:5931-5938. 
25. Daugaard $M$, Rohde $M$, Jäättelä $M$ : The heat shock protein 70 family: Highly homologous proteins with overlapping and distinct functions. FEBS Lett 2007, 581:3702-3710.

26. Creagh EM, Carmody RJ, Cotter TG: Heat shock protein 70 inhibits caspase-dependent and -independent apoptosis in Jurkat T cells. Exp Cell Res 2000, 257:58-66.

27. Lee YY, Wong KT, Tan J, Toh PC, Mao Y, Brusic V, Yap MG: Overexpression of heat shock proteins (HSPs) in CHO cells for extended culture viability and improved recombinant protein production. J Biotechnol 2009, 143:34-43.

28. Lasunskaia EB, Fridlianskaia II, Darieva ZA, da Silva MS, Kanashiro MM, Margulis BA: Transfection of NSO myeloma fusion partner cells with HSP70 gene results in higher hybridoma yield by improving cellular resistance to apoptosis. Biotechnol Bioeng 2003, 81:496-504.

29. Ishaque A, Thrift J, Murphy JE, Konstantinov K: Over-expression of Hsp70 in BHK-21 cells engineered to produce recombinant factor VIII promotes resistance to apoptosis and enhances secretion. Biotechnol Bioeng 2007, 97:144-155.

30. Meunier L, Usherwodd YK, Chung KT, Hendershot LM: A subset of chaperones and folding enzymes form multiprotein complexes in endoplasmic reticulum to bind nascent proteins. Mol Biol Cell 2002, 13:4456-4469.

31. Alete DE, Racher AJ, Birch JR, Stansfield SH, James DC, Smales CM: Proteomic analysis of enriched microsomal fractions from GS-NSO murine myeloma cells with varying secreted recombinant monoclonal antibody productivities. Proteomics 2005, 5:4689-4704.

32. Van Anken E, Romijn EP, Maggioni C, Mezghrani A, Sitia R, Braakman I, Heck AJ: Sequential waves of functionally related proteins are expressed when B cells prepare for antibody secretion. Immunity 2003, 18:243-253.

33. Seth G, Charaniya S, Wlaschin KF, Hu WS: In pursuit of a super producer alternative paths to high producing recombinant mammalian cells. Curr Opin Biotechnol 2007, 18:557-564.

34. Jha S, Dutta A: RVB1/RVB2: Running rings around molecular biology. Mol Cell 2009, 34:521-533.

35. McKanna JA: Lipocortin 1 in apoptosis: mammary regression. Anat Rec 1995, 242:1-10.

36. Wu YL, Jiang XR, Lillington DM, Newland AC, Kelsey SM: Upregulation of lipocortin 1 inhibits tumour necrosis factor-induced apoptosis in human leukaemic cells: a possible mechanism of resistance to immune surveillance. Br J Haematol 2000, 111:807-816.

37. Piljic A, Schultz C: Annexin A4 self-association modulates general membrane protein mobility in living cells. Mol Biol Cell 2006, 17:3318-3328

38. Riera J, Lazo PS: The mammalian NudC-like genes: a family with other functions other than regulating nuclear distribution. Cell Mol Life Sci 2009, 66:2383-2390.

39. Aniento F, Emans N, Griffiths G, Gruenberg J: Cytoplasmic dyneindependent vesicular transport from early to late endosomes. J Cell Biol 1993, 123:1373-1387.

40. Rozenblum GT, Calponins MGimona: Adaptable modular regulators of the actin cytoskeletal. Int J Biochem Cell Biol 2008, 40:1990-1995.

doi:10.1186/1472-6750-11-78

Cite this article as: Meleady et al: Sustained productivity in recombinant Chinese Hamster Ovary $(\mathrm{CHO})$ cell lines: proteome analysis of the molecular basis for a process-related phenotype. BMC Biotechnology 2011 11:78.

\section{Submit your next manuscript to BioMed Central and take full advantage of:}

- Convenient online submission

- Thorough peer review

- No space constraints or color figure charges

- Immediate publication on acceptance

- Inclusion in PubMed, CAS, Scopus and Google Scholar

- Research which is freely available for redistribution

Submit your manuscript at www.biomedcentral.com/submit
Biomed Central 